\title{
Using high titer West Nile intravenous immunoglobulin from selected Israeli donors for treatment of West Nile virus infection
} David Ben-Nathan*1,2, Orly Gershoni-Yahalom¹, Itzchak Samina², Yevgeny Khinich ${ }^{2}$, Israel Nur ${ }^{3}$, Orgad Laub ${ }^{3}$, Ahuva Gottreich ${ }^{4}$, Michael Simanov ${ }^{2}$, Angel Porgador ${ }^{1}$, Bracha Rager-Zisman ${ }^{1}$ and Nadav Orr ${ }^{3}$

Address: ${ }^{1}$ The Shraga Segal Dept. of Microbiology and Immunology, Ben Gurion University, Beer Sheva, Israel, ${ }^{2}$ Kimron Veterinary Institute, Department of Virology, Beit Dagan, Israel, ${ }^{3}$ OMRIX Biopharmaceuticals, Weizmann Science Park, Ness-Ziona, Israel and ${ }^{4}$ MDA National Blood Services, Tel Hashomer, Kiryat Ono, Israel

Email: David Ben-Nathan* - davidbn@013.net.il; Orly Gershoni-Yahalom - orlyge@bgu.ac.il; Itzchak Samina - isami@moag.gov.il; Yevgeny Khinich - vaccine@moag.gov.il; Israel Nur - israel@omrix.co.il; Orgad Laub - orgad@omrix.co.il;

Ahuva Gottreich - ahuva@sheba.health.gov.il; Michael Simanov - vaccine@moag.gov.il; Angel Porgador - angel@bgu.ac.il; Bracha RagerZisman - rager@netvision.net.il; Nadav Orr - nadav@omrix.co.il

* Corresponding author

Published: 17 February 2009

BMC Infectious Diseases 2009, 9:18 doi:10.1/86/1471-2334-9-18
Received: 8 August 2008

Accepted: 17 February 2009

This article is available from: http://www.biomedcentral.com/I47/ -2334/9//8

(C) 2009 Ben-Nathan et al; licensee BioMed Central Ltd.

This is an Open Access article distributed under the terms of the Creative Commons Attribution License (http://creativecommons.org/licenses/by/2.0), which permits unrestricted use, distribution, and reproduction in any medium, provided the original work is properly cited.

\begin{abstract}
Background: West Nile Virus (WNV) is endemic in Israel and a significant level of antibodies is present in the population due to natural exposure. Anecdotal cases suggested that the presence of anti-WNV antibodies in intravenous immunoglobulin (IVIG) from Israeli donors (IVIG-IL) assisted the recovery of patients with severe WNV infection.

Methods: To enhance the therapeutic efficacy of IVIG-IL against WNV infection, OMRIX Biopharmaceuticals, Israel, have developed a strategy for selection of plasma units from a $10 \%$ fraction of Israeli blood donors with anti-WNV antibodies. Positive units were processed into pharmaceutical grade WNV IVIG (WNIG). Following inoculation with WNV, mice received i.p. injections of different doses $(0.01-8 \mathrm{mg} /$ mouse) of IVIG-IL or WNIG, according to the specific experimental protocol.
\end{abstract}

Results: WNIG was about 10 times more potent (per gr of lgG) than was regular IVIG-IL when tested by ELISA and neutralization assays. In a mouse lethal WNV infection model, prophylactic treatment with WNIG was at least 5-10-fold more potent as compared to treatment with IVIGIL. Treatment with WNIG during active encephalitis, three or four days following WNV infection, had a significant protective effect. WNIG was also very effective in protecting immunosuppressed mice. Indeed, treatment of dexamethasone-immunosuppressed mice with 0.2 or $1.0 \mathrm{mg}$ WNIG 4 $\mathrm{h}$ after virus infection, led to $100 \%$ survival.

Conclusion: IVIG produced from selected plasma donated in WNV endemic regions can be used to produce WNV IVIG with superior activity for therapeutic and prophylactic measures. 


\section{Background}

Passive transfer of antibodies has been shown to be effective for the prevention and treatment of many infectious diseases, including those caused by viruses [1]. Intravenous human immunoglobulin produced from pooled plasma (IVIG) is the major source for antibody therapy by virtue of the diverse repertoire of immunoglobulin molecules responsible for a wide spectrum of anti-bacterial and anti-viral activities [2]. The pooled plasma of subjects that had been naturally exposed to pathogens has been used for the production of IVIG preparations containing specific antibodies for treatment of disease causing viruses, including Cytomegalovirus, Hepatitis A, B and C, HIV, Respiratory Syncytial Virus, Measles and Varicella Zoster virus [1].

West Nile virus (WNV), a mosquito-transmitted flavivirus, was first isolated from a febrile adult woman in the West Nile District of Uganda in 1937 [3]. WNV is a single stranded plus RNA virus, and a member of the Japanese encephalitis antigenic complex of the genus Flavivirus, family Flaviviridae [4,5]. Until 1999, West Nile Virus was found in Africa, the Middle East, parts of Asia, Southern Europe and Australia. It then suddenly emerged in New York, rapidly spread throughout the United States and has since caused considerably acute mortality and morbidity [6]. The clinical manifestations of WNV in humans range from asymptomatic seroconversion to fatal meningoencephalitis, with symptoms including cognitive dysfunction, muscle weakness and flaccid paralysis [7-10]. Depressed immunity, age and genetic factors $[11,12]$ are correlated with greater risk for neurological disease. Currently, there is no effective anti-viral therapy or human vaccine for $\mathrm{WNV}$ infection.

Available evidence suggests that WNV might be more susceptible to antibody-mediated than cell-mediated immunity. Indeed, passive transfer of specific antibodies (Ab) or immunoglobulin has been shown to abort or modify West Nile viral infections in animal models in a dosedependent manner [13-15]. WNV is endemic in Israel and significant levels of anti-WNV Ab are found in commercial preparations of IVIG prepared from the plasma of Israeli donors (IVIG-IL). Anecdotal cases have suggested that the presence of anti-WNV Ab in IVIG-IL assisted the recovery of patients suffering from severe WNV infection $[16,17]$. We have previously shown that while IVIG-IL protected mice against lethal doses of $\mathrm{WNV}$, the low exposure to the virus of US donors resulted in no effect of IVIG produced from the plasma of US donors (IVIG-US) $[13,18]$. Recently, however, it has been shown that some IVIG preparations produced in the USA during epidemic years contained antibodies against WNV and thus, were protective in an animal model for WNV infection [19].
In order to enhance the therapeutic efficacy of IVIG against WNV infection, OMRIX biopharmaceuticals firm has developed a strategy for the selection of plasma units from the $10 \%$ fraction of blood donors containing WNV antibodies. Positive units were processed into pharmaceutical grade WNV IVIG (WNIG). The potency of WNIG for the neutralization of WNV NY99 strain was tested in vitro by a cell neutralizing assay and in vivo, using a mouse lethal model. WNIG was at least 5-10-fold more potent than was regular IVIG-IL. Treatment with WNIG three or four days after challenge was also efficacious. We conclude that blood from selected donors in WNV endemic regions can improve the potency of IVIG and should be developed for use in therapy and for prophylactic measures.

\section{Methods \\ Mice}

Female BALB/cOlaHsd mice (4-5 weeks old, 15-17 g at study initiation; Harlan Laboratories, Israel) were used, unless otherwise stated. Mice were maintained in isolation cages throughout the study and fed and watered ad libitum. The mouse experiments were approved and performed according to the Kimron Veterinary Institute guidelines for animal experimentation with arboviruses.

\section{Cell Cultures}

Vero cells (ATCC \#CRL-1587) were grown in Dulbecco's Modified Eagle Medium (DMEM) supplemented with $10 \%$ fetal calf serum (FCS), $1 \%$ nonessential amino acids, $1.2 \% \mathrm{NaHCO}_{3}$ and antibiotics. The cells were maintained in a humidified atmosphere at $37^{\circ} \mathrm{C}$ containing $5 \% \mathrm{CO}_{2}$ and were used for growing virus stocks and virus titration.

\section{Virus stocks and virus titrations}

WNV-NY99 (3rd passage in Vero cells of strain NY 38599) [20], was kindly provided to OMRIX biopharmaceuticals by M.S. Diamond, Washington University, School of Medicine, St. Louis, MO, USA. Virus plaque assays were performed on Vero cells as previously described [21] and virus titers were expressed as plaque-forming units (PFU)/ $\mathrm{ml}$. A single virus stock containing $5 \times 10^{8} \mathrm{PFU} / \mathrm{ml}$ was stored in aliquots at $-70^{\circ} \mathrm{C}$ and was used in all studies.

\section{Infection and challenge of mice}

In all experiments (unless otherwise stated), 4-5 week old mice were inoculated intraperitoneally (i.p.) with $0.2 \mathrm{ml}$ of coctail containing different quantities of stock virus per mouse [18]. Lethal dose $50\left(\mathrm{LD}_{50}\right)$ was calculated according to the method of Reed and Muench [22].

\section{Immunoglobulin (IVIG) preparations}

OMRIX IVIG preparations (Omr-IgG-am ${ }^{\mathrm{TM}}$, OMRIX biopharmaceuticals, Israel) contain $5 \%$ protein, consisting more than $99 \%$ IgG and a very small quantities of IgA and 
IgM. Three preparations (5\% IVIG, produced by OMRIX) were employed (Table 1): (a) High titer WNV-IVIG (WNIG), Batch \#K44G511. This product was prepared during 2006 from Israeli plasma that was pre-screened by ELISA for specific anti-WNV antibodies. About 10\% of the plasma units from the general blood donor population had > 100 arbitrary units/ml (AU/ml) of anti-WNV antibodies. These units were pooled for the production of WNIG. (b) Commercial IVIG-IL batch \#H23131, prepared in 2003, from pooled plasma of Israeli blood donors. (c) Commercial IVIG-US Batch \#K30G370, prepared in 2006 from pooled plasma of US blood donors.

\section{Antigen preparation}

Inactivated WNV antigen was prepared by inactivation of the stock virus with -Propiolactone $(0.001 \%$ final concentration) $[18,23]$.

\section{Detection of anti-WNV antibodies by ELISA}

\section{a. ELISA for human antibodies}

A quantitative ELISA was developed at OMRIX based on the method described earlier [18]. To allow quantitative measurements, a specific positive plasma sample was assigned a value of $2000 \mathrm{AU} / \mathrm{ml} \mathrm{WNV}$ antibodies. This sample served as a calibration standard. The 1-10 AU/ml range was found to display linear characteristics when the log-transformation of concentration was plotted against the observed optical density at $405 \mathrm{~nm}$. Briefly, microtiter plates were first coated with inactivated WNV antigen in carbonate buffer, $\mathrm{pH}$ 9.6. The plates were blocked with $0.5 \%$ I-block (Tropix, Bedford, MA) and 10\% goat serum. Samples and controls were diluted in blocking buffer to fit the standard curve range. Alkaline phosphatase-conjugated goat anti-human IgG (Sigma, Israel) was added as a detector followed by pNPP substrate (Sigma, Israel). The titer of each serum and control sample was calculated from absorbance at $405 \mathrm{~nm}$ plotted against the log transformation of calibrator concentration.

Table I: Anti-WNV antibodies in the IVIG preparations used for treatments

\begin{tabular}{ccccccc}
\hline & \multicolumn{2}{c}{ Titer by ELISA } & & \multicolumn{2}{c}{ Titer by PRNT $_{50}$} \\
\cline { 2 - 3 } \cline { 5 - 6 } IVIG Preparation & AU/ml & AU/mg & & WNU/ml & WNU/mg \\
\hline WNIG & 7608 & 152 & & 9900 & 198 \\
IVIG-IL & 668 & 13 & & 1032 & 21 \\
IVIG-US & 179 & 4 & & \multicolumn{2}{c}{ Not done }
\end{tabular}

WNIG, high titer anti-WNV IVIG (from selected donors); IVIG-IL, IVIG preparation from the pooled plasma of Israeli donors; IVIG-US, IVIG preparation from the pooled plasma of US donors. AU, arbitrary units of anti-WNV antibodies per mouse (as assessed by ELISA, see Methods). WNU, the reciprocal of the highest dilution giving $50 \%$ reduction in a $\mathrm{PRNT}_{50}$ assay.

\section{b. ELISA for mouse sera}

An ELISA test was performed according to the method described by Martin et al. [24], with slight modifications [18]. Specific titers were expressed as the reciprocal of the highest dilution giving a reading above the cut-off value [25].

\section{Plaque Reduction Neutralization Titer 50\% (PRNT50)}

The titer of neutralizing antibodies was determined using a plaque reduction test based on the method described earlier [18]. Briefly, samples were diluted by serial twofold dilutions $(1: 10-1: 10,240)$ in DMEM, 2\% FCS and mixed with an equal volume of similar medium containing approx. $450 \mathrm{PFU} / \mathrm{ml}$ of WNV NY99. The mixtures were incubated overnight at $4{ }^{\circ} \mathrm{C}$ on a roller and the virus-antibody mixtures $(400 \mu \mathrm{l})$ were then added to Vero cells preseeded in 6-well plates at a concentration of $5 \times 10^{5}$ cells/ well and pre-grown overnight at $37^{\circ} \mathrm{C}, 5 \% \mathrm{CO}_{2}$. After 60 minutes at $37^{\circ} \mathrm{C}$ in $5 \% \mathrm{CO}_{2}$, the monolayers were overlaid with $3 \mathrm{ml}$ of Modified Eagle Medium (MEME) $\times 2$ and tragacanth (Sigma, Israel) containing 4\% FCS and $2.4 \%$ sodium bicarbonate. The cultures were incubated for an additional 72 hours at $37^{\circ} \mathrm{C}$ in $5 \% \mathrm{CO}_{2}$. The cells were then fixed with ethanol, stained with fucsin, and plaques were counted. $\mathrm{PRNT}_{50}$ values were expressed as the reciprocal of the highest dilution giving 50\% reduction in plaque numbers (WNU).

\section{Treatment with Immunoglobulins}

Following inoculation with $\mathrm{WNV}$, mice received i.p. injections of different doses of IVIG-IL, IVIG-US or WNIG, according to the specific experimental protocol. Treatment doses ranged from $0.01 \mathrm{mg} /$ mouse (about $0.6 \mathrm{mg} /$ $\mathrm{kg}$ ) to $8 \mathrm{mg} /$ mouse (about $470 \mathrm{mg} / \mathrm{kg}$ ). The animals were followed for mortality for at least 21 days.

\section{WNIG Therapy of immunosuppressed mice}

Seven to 8 weeks old mice received two subcutaneous (s.c.) doses of dexamethasone (Sigma, Israel, $60 \mu \mathrm{g} /$ mouse each). The first dose was administered 2 hours before inoculation with 5-10 PFU of WNV-NY99 and a second dose was administered 1 day thereafter. Four hours after inoculation with $\mathrm{WNV}$, the animals were treated i.p. with $1 \mathrm{mg}$ or $0.2 \mathrm{mg} /$ mouse of WNIG. The animals were followed for mortality for at least 21 days.

\section{Statistics}

Survival rates of the different groups were compared by Fisher's exact test. Average days for death were compared by Student's t-test.

\section{Results The protective effects of WNIG against lethal WNV infection}

To study the relative protective efficacy of WNIG, as compared to IVIG-IL or IVIG-US, mice were inoculated i.p. 
with 10-20 $\mathrm{LD}_{50}$ (50-100 PFU) of WNV-NY99, followed 4 hours later by treatment with a single injection of 2, 0.5 or $0.1 \mathrm{mg}$ of WNIG, IVIG-IL or IVIG-US. Treatment with 2 mg of WNIG/mouse or IVIG-IL was sufficient to confer $88-100 \%$ protection against $10-20 \mathrm{LD}_{50}$ of the virus (Table 2). As expected, IVIG-US showed lower protective efficacy, with only $63 \%$ survival after treatment with 2.0 $\mathrm{mg} /$ mouse. The superiority of WNIG was clearly demonstrated at a dose of $0.1 \mathrm{mg} /$ mouse, where IVIG-IL conferred only $44 \%$ protection, as compared to the $94 \%$ protection attained with WNIG.

These results suggest that the protective efficacy of $0.1 \mathrm{mg}$ WNIG was similar to that obtained with $0.5 \mathrm{mg}$ of IVIGIL, i.e. WNIG was at least 5-fold more efficacious. WNIG at $0.1 \mathrm{mg}$ showed a similar efficacy as IVIG-US at $2.0 \mathrm{mg}$, i.e. WNIG was some 20 -fold more efficacious. The superiority of WNIG was also demonstrated by comparing the levels of viremia in mice treated with IVIG-IL or WNIG before inoculation with 50 PFU of WNV. Treatment with $0.1 \mathrm{mg}$ IVIG-IL moderately decreased virus levels in the blood of infected animals from an average of 3.4 to 2.0 $\log _{10}$ PFU/ml on day 2 and from 2.9 to $1.8 \log _{10}$ PFU/ml on day 3. No virus was detected in the blood of mice treated with WNIG. About $6.2 \log _{10}$ PFU/brain were found on day 7 in brains of control-infected mice, while no virus was detected in the brains of IVIG-IL- or WNIGtreated mice (data not shown).

We further investigated the protective efficacy of lower doses of WNIG and IVIG-IL. Groups of mice were infected with $10 \mathrm{LD}_{50}$ (50 PFU) of WNV and treated 4 hours later with a single injection containing $0.05,0.025$ or $0.01 \mathrm{mg}$ of WNIG or $0.25 \mathrm{mg}$ of IVIG-IL. As shown in Figure 1, a 5-10 fold increase in protective efficacy of WNIG over IVIG-IL treatment was maintained, as revealed upon comparing treatment with $0.25 \mathrm{mg}$ IVIG-IL to treatment with $0.05-0.025 \mathrm{mg}$ WNIG. Mortality in these groups was delayed compared to that of the control-infected mice. In the untreated WNV-NY99 infected mice, all of the deaths occurred by day 8 . In the IVIG-IL ( $0.25 \mathrm{mg})$-treated mice, mortality was delayed and occurred between days 8-15. A similar pattern of delayed mortality was obtained after treatment with 0.05 or $0.025 \mathrm{mg}$ of WNIG.

\section{Detection of anti-WNV antibodies in surviving mice}

De-novo synthesis of anti-WNV antibodies in WNIGtreated, surviving mice was tested 21, 40 and 60 days after challenge and treatment. Animals were challenged with $10 \mathrm{LD}_{50} /$ mouse and $4 \mathrm{~h}$ later, were treated with WNIG or IVIG-IL (0.1-0.5 mg/mouse). Pooled serum samples were collected from surviving mice on days 21, 40 and 60 after treatment and antibody titers were assessed by ELISA. The surviving animals presented high levels of anti-WNV antibody titers ranging from 1:8,000-1:16,000. The high titers of anti-WNV antibodies were maintained for at least 60 days.

\section{Therapeutic efficacy of WNIG}

In the mouse model, active encephalitis can be detected 3 days after challenge with WNV $[18,32]$. To study the therapeutic efficacy of WNIG, mice were injected with $10 \mathrm{LD}_{50}$ of WNV, and treated with 2 mg WNIG or IVIG-IL on days 2 and 4 or 3 and 5 after infection. As shown in Figure 2, injection of $2 \mathrm{mg}$ of WNIG on days 2 and 4 after infection protected $100 \%$ of the animals, as compared with the $75 \%$ protection observed in mice receiving IVIG-IL. Treatment with WNIG on days 3 and 5 significantly delayed mortality of the infected mice. In this group, $62 \%$ of the animals survived for 17 days. The average period of death in the WNIG group treated on days 3 and 5 was 12.5 days $(S D=5.7)$, while the average period of death in the IVIGIL group treated 3 and 5 days after infection and in untreated mice were 7.1 days $(\mathrm{SD}=1.1)$ and 6.6 days $(\mathrm{SD}$ $=0.5$ ), respectively ( $\mathrm{p}=0.032$ for the WNIG group as compared to the IVIG-IL group; $\mathrm{p}=0.048$ for the WNIG group as compared to untreated group).

To assess the therapeutic effect offered by a higher dose of WNIG, a single dose of $8 \mathrm{mg} /$ mouse was given on days 3 ,

Table 2: Protective efficacy of WNIG, IVIG-IL and IVIG-US in mice infected with I0-20 LD $_{50}$ of WNV NY99

\begin{tabular}{ccc}
\hline Treatment $(\mathrm{mg} / \mathrm{mouse})$ & Specific Ab dose $^{\mathrm{a}}$ & Percent survival (live/treated) \\
\hline No treatment & 0 & $7(1 / 14)^{\mathrm{b}}$ \\
WNIG (0.1 mg) & 15 & $94(15 / 16)^{\mathrm{c}}$ \\
IVIG-IL (0.1 mg) & 1.3 & $44(7 / 16)$ \\
WNIG (0.5 mg) & 76 & $100(16 / 16)$ \\
IVIG-IL (0.5 mg) & 7 & $87(14 / 16)$ \\
WNIG (2.0 mg) & 304 & $100(8 / 8)$ \\
IVIG-IL (2.0 mg) & 27 & $88(7 / 8)$ \\
IVIG-US (2.0 mg) & 7 & $63(5 / 8)$
\end{tabular}

Groups of 4-5 week-old BALB/c mice were treated i.p. with different amounts of WNIG or IVIG-IL, 4 h after injection of $10-20$ LD $_{50}$ of West Nile virus. Animals were observed daily for mortality for 21 days. aArbitrary units of anti-WNV antibodies per mouse (as assessed by ELISA, see Methods). ${ }^{b} p<0.039$, as compared to all treatment groups. ${ }^{c} p=0.006$, as compared to the IVIG-IL $(0.1 \mathrm{mg})$ group. 


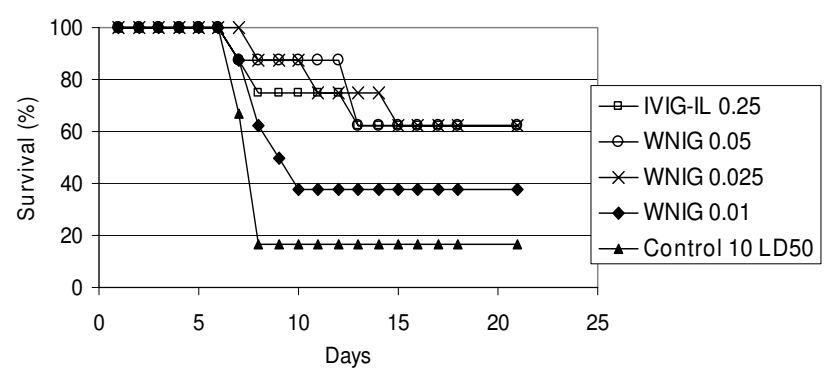

Figure I

Dose-dependent protection by WNIG. Groups of 5week old BALB/c mice were treated i.p. with IVIG-IL ( 0.5 or $0.25 \mathrm{mg} / \mathrm{mouse})$ or with WNIG (0.0I, 0.05 , or $0.025 \mathrm{mg} /$ mouse) $4 \mathrm{~h}$ after infection with $10 \mathrm{LD}_{50}$ of WNV NY99. Mice were observed for mortality for 21 days. One group of infected mice received no treatment (control).

4 , or 5 after infection. This dosage protected all of the animals when administered 3 days after infection (Table 3 ). When given 4 days after infection, the survival rate was $63 \%$ as compared to the $25 \%$ survival rate measured in the untreated control group. Treatment on day 5 after infection was not effective, suggesting that, at this point, the damage cause by the virus was irreversible.

\section{WNIG therapy of immunosuppressed mice}

Resistance to viral infection can be modified by treatment with dexamethasone $[21,26]$. Seven to 8 weeks old mice were chosen for this experiment, since we found that such mice are more resistant to low dose WNV infection than are younger animals (data not shown). Mice were injected s.c with two doses of $60 \mu \mathrm{g} /$ mouse of dexamethasone. The first dose was administered 2 h before infection with 5-10 PFU of WNV NY-99 strain. A second dose was administered 1 day later.

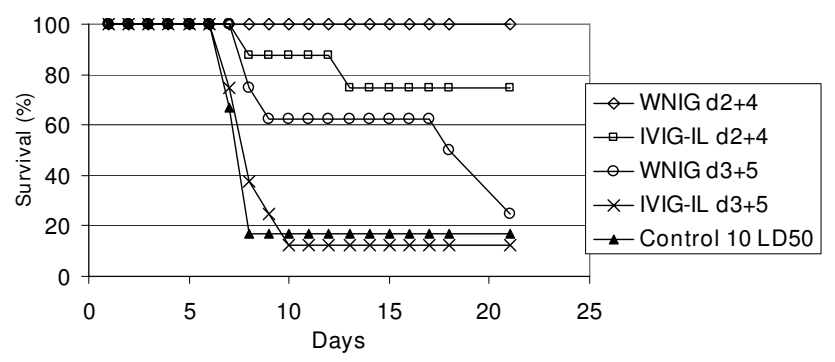

Figure 2

Therapeutic efficacy of WNIG. Groups of 5-week old BALB/c mice were treated i.p. with $2 \mathrm{mg} /$ mouse IVIG-IL or WNIG on days 2 and 4 , or days 3 and 5 after infection with 10 LD $_{50}$ of West Nile virus. Mice were observed for mortality for 21 days. One group of infected mice received no treatment (control).
Dexamethasone treatment increased the susceptibility of adult mice to $\mathrm{WNV}$, thereby lowering the survival rate from $58 \%$ to less than $19 \%$. Treatment of dexamethasoneimmunosuppressed mice with 0.2 or $1.0 \mathrm{mg}$ WNIG $4 \mathrm{~h}$ after viral infection resulted in $100 \%$ survival (Table 4 ).

\section{Discussion}

Antibody-based therapy against viral and bacterial infections has been successfully practiced since the end of the 19th century [27]. Since the emergence of West Nile virus (WNV) as an important pathogen in a number of regions, including the continental USA, the potential use of specific antibodies for protection and treatment of infections associated with WNV has been studied in several animal models, including different mouse strains and Syrian golden hamsters $[13,18,28-30]$.

We have previously shown, using a mouse model, that commercial preparations of IVIG from normal Israeli blood donors imparts protection to mice against viral infection. The emergence of WNV in many regions of the continental USA after 1999 has allowed others to confirm the efficacy in animal models, of IVIG produced from specific US regions [19]. Using a different approach, humanized monoclonal antibodies against specific epitopes in the viral envelope showing high in-vivo potency were developed [31]. Despite these successes it is still easier to develop a new formulation derived from a known pharmaceutical product with an excellent safety profile, such as IVIG [1]. Therefore, the use of IVIG with high WNV antibody levels is considered a leading approach for treatment of WNV infection. Although the potential use of IVIG from regions endemic for $\mathrm{WNV}$ has been was reported, a serious limiting factor in applying this concept is the relatively low levels of specific antibodies and very high batch-to-batch variance in WNV antibody levels, especially in IVIGs produced in countries such as the USA where the exposure of donors to WNV is limited and not homogenous [19]. Even in hyper-endemic regions such as Israel, only a fraction of the population has a history of exposure to WNV [17].

Our finding that only $8-10 \%$ of the plasma units from the normal donor population contributed almost all of the anti-WNV antibodies to the plasma pools allowed the development of a highly effective WNV treatment option The IVIG produced from positive WNV antibody-containing plasma units selected by ELISA, termed WNIG, showed promising potential in a cell neutralizing assay, with about 10-fold higher anti-WNV antibody levels being detected, as compared to regular IVIG-IL (9900 compared to $1032 \mathrm{WNU}$, by $\mathrm{PRNT}_{50}$, and 7608 compared to $668 \mathrm{AU}$, by ELISA, respectively). Indeed, good correlation was shown between the ELISA and $\mathrm{PRNT}_{50}$ results. 
Table 3: Protective efficacy of WNIG in mice infected with 10 LD $_{50}$ of WNV.

\begin{tabular}{ccc}
\hline Treatment day (after challenge) & Treatment dose (mg/mouse) & Percent survival (live/treated) \\
\hline No treatment & - & $25(2 / 8)$ \\
Day 0 & 2 & $100(8 / 8)$ \\
Day 0 & 8 & $100(8 / 8)$ \\
Day 3 & 8 & $100(8 / 8)$ \\
Day 4 & 8 & $63(5 / 8)$ \\
Day 5 & 8 & $38(3 / 8)$ \\
\hline
\end{tabular}

Groups of 4-5 week-old BALB/c mice were treated i.p. with WNIG (2 or $8 \mathrm{mg} / \mathrm{mouse}$ ), $4 \mathrm{~h}$, or on days 3, 4, or 5 after injection of $10-20$ LD $_{50}$ of WNV. Mice were observed daily for mortality for 21 days.

Tests in mice confirmed the in vitro analysis by showing 510 fold enhancement (per $g$ of total IgG) of efficacy when compared to regular IVIG-IL produced from Israeli donors and at least one log increase compared to IVIG-US produced from US donors.

When considering WNIG as a practical clinical option, treatment of patients with active encephalitis should be evaluated. The penetration of antibodies across the blood brain barrier (BBB) is highly inefficient but it is speculated that during active disease, the BBB becomes partially permeable thereby allowing penetration of significant quantities of antibodies to the infected site. As the level of antibodies in the serum is directly correlated to antibody levels in the brain, the goal of any treatment is to supply as many antibodies as possible, especially when trying to combat active disease. The protective effects of IVIG and monoclonal antibodies against infection already established in the brain was previously shown in animal models $[15,18,28]$. In human, intravenous immunoglobulin treatment was reported to be associated with improvement and elimination of the signs and symptoms of WNV infection $[16,17]$. Our results support the superiority of WNIG over regular IVIG-IL when given to mice even 3 or 4 days after infection, at the point where WNV had already established infection in the brain [18,32]. Augmenting the level of antibodies against WNV may thus prove to be an important treatment strategy for infection, particularly

Table 4: Therapy of immunosuppressed mice by WNIG.

\begin{tabular}{cc}
\hline Treatment group & Survival \% (live/treated) \\
\hline WNV control & $58(7 / 12)$ \\
Dexamethasone & $19(3 / 16)^{\mathrm{a}}$ \\
Dex + WNIG $(1.0 \mathrm{mg} /$ mouse $)$ & $100(17 / 17)$ \\
Dex + WNIG $(0.2 \mathrm{mg} /$ mouse $)$ & $100(16 / 16)$ \\
\hline
\end{tabular}

Group of 7-8 week-old BALB/c mice received two s.c. injection of 60 $\mu \mathrm{g} / \mathrm{mouse}$, dexamethasone (Dex), 2 hours before, and one day after infection with WNV. Mice were treated i.p. with WNIG (I.0 or 0.2 $\mathrm{mg} / \mathrm{mouse}), 4 \mathrm{~h}$ after infection with 5-10 PFU of WNV. Mice were observed daily for mortality for 21 days. No mortality was observed in no-infected dexamethasone-treated mice.

${ }^{a} \mathrm{p}<0.001$, as compared to the WNIG $(0.2-1.0 \mathrm{mg})$ group. for the elderly and those with immune systems deficiencies [33]. Immuno-compromised subjects represent a major target population for passive antibody treatment or prophylaxis against WNV infection. Concomitant administration of dexamethasone and pathogens leads to widespread suppression of the innate immune response [26], enhanced viral replication and mortality [21]. It was shown that a broad range, non-specific immunosuppression increases the sensitivity of golden hamsters to WNV infection [34]. Engle and Diamond [28] showed that antibodies can only partially restore the protection against WNV infection thus suggesting that an efficient anti-viral response requires the combined activities of the innate and specific immune systems. However, we show here that WNIG alone was highly effective even when coadministered with the aggressive immuno-suppression agent, dexamethasone, which affects the innate immunity [26]. Treatment with WNIG offered complete protection to mice injected with dexamethasone, while the mortality among control infected mice injected with dexamethasone exceeded $80 \%$.

When considering the practical application of passive immunotherapy to fight $\mathrm{WNV}$ infection, the total quantity of specific antibodies administered is limited by the maximum quantity of IVIG allowed for IV infusion (up to $2 \mathrm{~g} /$ $\mathrm{kg}$ ). The use of WNIG will allow the administration of 510 times more specific antibodies, as compared to regular IVIG-IL, thus providing significantly enhanced therapeutic potential.

\section{Conclusion}

The protective efficacy of WNIG, when administered 3 and 4 days after infection, suggests that the use of IVIG containing a high titer anti-WNV antibodies offers great potential for controlling active infection, even in the CNS. The possibility of exploiting the augmented levels of specific antibodies in a small fraction of the population by selection of plasma units before processed into IVIG will allow for the use of acceptable doses of IgG in patients, thereby increasing their chances for survival or lowering the risks of immediate and/or long term adverse effects. 


\section{Abbreviations}

Ab: antibodies; DMEM: Dulbecco's modified eagle medium; FCS: fetal calf serum; i.p.: intraperitoneal; IVIG: intravenous immunoglobulin; IVIG-IL: IVIG prepared from plasma of Israeli blood donors; IVIG-US: IVIG prepared from plasma of US blood donors; LD50: lethal dose 50\%; MEM: modified eagle medium; PFU: plaque forming units; s.c.: subcutaneous; WNIG: IVIG prepared from plasma of Israeli blood donors with anti-WNV antibodies; WNV: West Nile virus.

\section{Competing interests}

DBN, OGY, IS, YK, AG, MS, AP and BRZ declare that they have no competing interests. NO, IN and OL are employees of OMRIX Biopharmaceuticals.

\section{Authors' contributions}

DBN and NO were responsible for the animal studies design, results interpretation and drafting the manuscript; IN, OL and NO were involved in concept development, IVIG production and characterization and study design. OGY carried out the mouse ELISA assays under the supervision of AP. IS, YK and MS were involved in the animal study designs and had a critical technical contribution to the animal model. BRZ contributed in all aspects of the animal study design and data interpretation. All of the authors were involved in critical reading of the manuscript and read and approved the final manuscript.

\section{Acknowledgements}

This work was supported in part by $\mathrm{NIH}$ grant \# I-UOI-AI06 I4 I7-0I and by grants from BGNegev and Center for the Study of Infectious Diseases, Ben-Gurion University, Beer Sheva, Israel.

The authors wish to thank Dana Sela and Barak Ramati at OMRIX R\&D laboratory for their technical assistance.

\section{References}

I. Keller MA, Stiehm ER: Passive immunity in prevention and treatment of infectious diseases. Clin Microbiol Rev 2000, |3:602-614.

2. Casadevall A, Dadachova E, Pirofski LA: Passive antibody therapy for infectious diseases. Nat Rev Microbiol 2004, 2:695-703.

3. Smithburn KC, Hughes TP, Burke AW, Paul JH: A neutrotropic virus isolated from the blood of a native of Uganda. Am J Trop Med 1940, 20:47I-492.

4. Burke SD, Monath TP: Flaviviruses. In Fields Virology Edited by: Field BN, Knipe DM, Howley PM. Philadelphia: Lippincott-Raven; 200I.

5. Scherret JH, Poidinger M, Mackenzie JS, Broom AK, Deubel V, Lipkin WI, Briese T, Gould EA, Hall RA: The relationships between West Nile and Kunjin viruses. Emerg Infect Dis 200I, 7:697-705.

6. Nash D, Mostashari F, Fine A, Miller J, O'Leary D, Murray K, Huang A, Rosenberg A, Greenberg A, Sherman M, et al.: The outbreak of West Nile virus infection in the New York City area in 1999. $N$ Engl J Med 200I, 344:|807-18|4.

7. Carson PJ, Konewko P, Wold KS, Mariani P, Goli S, Bergloff P, Crosby RD: Long-term clinical and neuropsychological outcomes of West Nile virus infection. Clin Infect Dis 2006, 43:723-730.

8. Debiasi RL, Tyler KL: West Nile virus meningoencephalitis. Nat Clin Pract Neurol 2006, 2:264-275.

9. Hayes EB, Gubler DJ: West Nile virus: epidemiology and clinical features of an emerging epidemic in the United States. Annu Rev Med 2006, 57:181-194.
10. Hayes EB, Komar N, Nasci RS, Montgomery SP, O'Leary DR, Campbell GL: Epidemiology and transmission dynamics of West Nile virus disease. Emerg Infect Dis 2005, I I:I I67-I I73.

II. Glass WG, McDermott DH, Lim JK, Lekhong S, Yu SF, Frank WA, Pape J, Cheshier RC, Murphy PM: CCR5 deficiency increases risk of symptomatic West Nile virus infection. J Exp Med 2006, 203:35-40.

12. Yakub I, Lillibridge KM, Moran A, Gonzalez OY, Belmont J, Gibbs RA, Tweardy DJ: Single nucleotide polymorphisms in genes for 2'5 '-oligoadenylate synthetase and RNase $L$ inpatients hospitalized with West Nile virus infection. J Infect Dis 2005, 192: 174|-1748.

13. Agrawal AG, Petersen LR: Human immunoglobulin as a treatment for West Nile virus infection. J Infect Dis 2003, 188:I-4.

14. Diamond MS: Development of effective therapies against West Nile virus infection. Expert Rev Anti Infect Ther 2005, 3:93I-944.

15. Morrey JD, Siddharthan V, Olsen AL, Roper GY, Wang H, Baldwin TJ, Koenig S, Johnson S, Nordstrom JL, Diamond MS: Humanized monoclonal antibody against West Nile virus envelope protein administered after neuronal infection protects against lethal encephalitis in hamsters. J Infect Dis 2006, 194:1300-1308.

16. Hamdan A, Green P, Mendelson E, Kramer MR, Pitlik S, Weinberger $M$ : Possible benefit of intravenous immunoglobulin therapy in a lung transplant recipient with West Nile virus encephalitis. Transpl Infect Dis 2002, 4:160-162.

17. Shimoni Z, Niven MJ, Pitlick S, Bulvik S: Treatment of West Nile virus encephalitis with intravenous immunoglobulin. Emerg Infect Dis 200I, 7:759.

18. Ben-Nathan D, Lustig S, Tam G, Robinzon S, Segal S, Rager-Zisman B: Prophylactic and therapeutic efficacy of human intravenous immunoglobulin in treating West Nile virus infection in mice. J Infect Dis 2003, 188:5-12.

19. Planitzer CB, Modrof J, Kreil TR: West Nile virus neutralization by US plasma-derived immunoglobulin products. J Infect Dis 2007, 196:435-440.

20. Steele KE, Linn MJ, Schoepp RJ, Komar N, Geisbert TW, Manduca RM, Calle PP, Raphael BL, Clippinger TL, Larsen T, et al.: Pathology of fatal West Nile virus infections in native and exotic birds during the 1999 outbreak in New York City, New York. Vet Pathol 2000, 37:208-224.

21. Ben-Nathan D, Lustig S, Kobiler D: Cold stress-induced neuroinvasiveness of attenuated arboviruses is not solely mediated by corticosterone. Arch Virol 1996, I41:1221-1229.

22. Reed LJ, Muench $\mathrm{H}$ : A simple method of estimating fifty percent end points. Am J Hyg 1938, 27:493-497.

23. Mahy BWJ, Kangro HO: Whole cells antigen preparations London: Academic Press, Harcourt Brace \& Company; 1996.

24. Martin DA, Muth DA, Brown T, Johnson AJ, Karabatsos N, Roehrig JT: Standardization of immunoglobulin $M$ capture enzymelinked immunosorbent assays for routine diagnosis of arboviral infections. J Clin Microbiol 2000, 38:1823-1826.

25. Frey A, Di Canzio ], Zurakowski D: A statistically defined endpoint titer determination method for immunoassays. J Immunol Methods 1998, 221:35-41.

26. Moynagh PN: Toll-like receptor signalling pathways as key targets for mediating the anti-inflammatory and immunosuppressive effects of glucocorticoids. J Endocrinol 2003, 179:।39-| 44.

27. Casadevall A: Passive antibody administration (immediate immunity) as a specific defense against biological weapons. Emerg Infect Dis 2002, 8:833-84I.

28. Engle MJ, Diamond MS: Antibody prophylaxis and therapy against West Nile virus infection in wild-type and immunodeficient mice. J Virol 2003, 77:|294|-12949.

29. Haley M, Retter AS, Fowler D, Gea-Banacloche J, O'Grady NP: The role for intravenous immunoglobulin in the treatment of West Nile virus encephalitis. Clin Infect Dis 2003, 37:e88-90.

30. Roehrig JT, Staudinger LA, Hunt AR, Mathews JH, Blair CD: Antibody prophylaxis and therapy for flavivirus encephalitis infections. Ann N Y Acad Sci 2001 I, 95 I:286-297.

31. Oliphant T, Engle M, Nybakken GE, Doane C, Johnson S, Huang L, Gorlatov S, Mehlhop E, Marri A, Chung KM, et al.: Development of a humanized monoclonal antibody with therapeutic potential against West Nile virus. Nat Med 2005, I I:522-530. 
32. Halevy M, Akov Y, Ben-Nathan D, Kobiler D, Lachmi B, Lustig S: Loss of active neuroinvasiveness in attenuated strains of West Nile virus: pathogenicity in immunocompetent and SCID mice. Arch Virol 1994, 137:355-370.

33. Gould LH, Sui J, Foellmer H, Oliphant T, Wang T, Ledizet M, Murakami A, Noonan K, Lambeth C, Kar K, et al.: Protective and therapeutic capacity of human single-chain Fv-Fc fusion proteins against West Nile virus. J Virol 2005, 79: | 4606-I 46 I3.

34. Mateo R, Xiao SY, Guzman H, Lei H, Da Rosa AP, Tesh RB: Effects of immunosuppression on West Nile virus infection in hamsters. Am J Trop Med Hyg 2006, 75:356-362.

\section{Pre-publication history}

The pre-publication history for this paper can be accessed here:

http://www.biomedcentral.com/1471-2334/9/18/prepub

Publish with Bio Med Central and every scientist can read your work free of charge

"BioMed Central will be the most significant development for disseminating the results of biomedical research in our lifetime. "

Sir Paul Nurse, Cancer Research UK

Your research papers will be:

- available free of charge to the entire biomedical community

- peer reviewed and published immediately upon acceptance

- cited in PubMed and archived on PubMed Central

- yours - you keep the copyright 